\title{
Dylemat audiodeskryptora $w$ procesie przekładu audiowizualnego
}

\section{The dilemma of an audio descriptor in the process of audiovisual translation}

\author{
Damian Wątrobiński \\ WYDZIAŁ NEOFILOLOGII, UNIWERSYTET IM. ADAMA MICKIEWICZA \\ AL. NIEPODLEGŁOŚCI 4, 61-874 POZNAŃ \\ damian.watrobinski@amu.edu.pl
}

\begin{abstract}
The aim of this article is to point out the dilemma concerning the transmission of emotions which faces the audio descriptor when creating audio description for painting reproductions. It will indicate the importance of visual forms, dependencies between the translator, translation and emotions, as well as different approaches to the creation of audio description, with particular emphasis on the transfer of emotions. The theoretical considerations will be supplemented by a qualitative analysis of two emotionally colored audio descriptions.
\end{abstract}

\section{Formy (audio)wizualne i ich znaczenie}

Kino, teatr i muzeum to instytucje udostępniające utwory (audio)wizualne, czyli takie, które my - odbiorcy (widzowie) - możemy kontemplować głównie za pomocą zmysłów wzroku i słuchu. Wśród wspomnianych wyżej utworów znajdują się $\mathrm{m}$. in. filmy różnego gatunku, przedstawienia teatralne, obrazy malarskie, bądź zdjęcia fotograficzne. W przypadku filmu i historii wystawianych na deskach teatru mamy do czynienia $\mathrm{z}$ formami sztuki, które swój wyraz znajdują w postaci obrazów ruchomych nagrywanych za pomocą kamery, bądź rozgrywających się na żywo, co ma miejsce $\mathrm{w}$ teatrach - oraz $\mathrm{w}$ postaci dźwięku pochodzącego ze świata przedstawionego $\mathrm{w}$ filmie oraz $\mathrm{z}$ dialogów prowadzonych przez postaci teatralne. Natomiast w przypadku obrazów malarskich i zdjęć kwestia dźwiękowa nie ma zastosowania i percepcja tychże form sztuki zostaje ograniczona jedynie do zmysłu wzroku, czyli stanowi ona źródło emocji i przeżycia jedynie dla wybranych osób - tych, które widzą. Ale co z osobami niewidomymi lub niedowidzącymi, dla których wskazane powyżej utwory 
wizualne są z zasady niedostępne? Każdy człowiek ma przecież prawo do uczestniczenia w życiu kulturalno-społecznym, które skłania do głębszych refleksji, kształtuje naszą osobowość, urozmaica życie prywatne i rozwija naszą sferę uczuciową. Sztuka i jej całe dobrodziejstwo artystycznoemocjonalne wydają się nieodzownym elementem życia każdego człowieka, a, co jest pewne, ich zasoby powinny być dostępne dla wszystkich bez wyjątku i bez jakichkolwiek ograniczeń. Na poparcie tych słów warto przytoczyć w tym miejscu artykuł 27 Powszechnej Deklaracji Praw Człowieka, który w swej treści odnosi się do sztuki i jej niczym nieograniczonego odbioru:

„Każdy człowiek ma prawo do swobodnego uczestniczenia w życiu kulturalnym społeczeństwa, do korzystania ze sztuki, do uczestniczenia w postępie nauki i korzystania z jego dobrodziejstw. Każdy człowiek ma prawo do ochrony moralnych i materialnych korzyści wynikających $\mathrm{z}$ jakiejkolwiek jego działalności naukowej, literackiej lub artystycznej."

Mimo że Powszechna Deklaracja Praw Człowieka, uchwalona przez Zgromadzenie Ogólne ONZ w dniu 10 grudnia 1948 roku w Paryżu, była w momencie jej powstania jedynie standardem, pewnymi zaleceniami i nie miała charakteru wiążącego, to w chwili obecnej uważana jest przez wielu prawników zajmujących się prawem międzynarodowym jako prawo zwyczajowe. Ponadto deklaracja ta została przetłumaczona na ponad 500 języków, co tylko pokazuje, że treści w niej zawarte, a w tym artykuł 27 dotyczący dostępu do sztuki, są przekazywane poprzez tłumaczenia do wielu społeczeństw, czyniąc te treści (poniekąd ideały) ważnymi, aktualnymi i pożądanymi.

\section{Audiodeskryptor w służbie osobom niewidomym}

W zarysowanym powyżej kontekście uwidacznia się jedna, szczególnie istotna kwestia - należy znaleźć taką formę przekazu, aby osoby niewidome i niedowidzące mogły dokonywać percepcji obrazów malarskich, mimo że nie mogą dostrzec ich warstwy wizualnej. Pomóc w tym może słowo, czyli opis audiowizualny, składający się ze słów dobranych przez audiodeskryptora. Audiodeskryptor, zwany również audiodeskryberem (por. Walczak 2012) to osoba, która tworzy opis, tzw. audiodeskrypcję, do utworów (audio)wizualnych, który jest następnie odczytywany przez lektora. Opis ten może być wpleciony do filmu pomiędzy dialogi, muzykę $\mathrm{i}$ dźwięki świata przedstawionego lub całkowicie stanowić substytut treści wizualnych, co ma miejsce w przypadku obrazów.

Chcąc umieścić pojęcia audiodeskrypcji [AD] i audiodeskryptora w dyskursie naukowym, a dokładniej rzecz ujmując, w obszarze nauk przekładoznawczych, należy wyjść od Jakobsona i jego teorii trzech rodzajów tłumaczenia (1971: 233), według której audiodeskrypcja daje się sklasyfikować jako przekład intersemiotyczny - w ramach audiodeskrypcji

${ }^{1}$ http://www.unesco.pl/fileadmin/user_upload/pdf/Powszechna_Deklaracja_Praw_Czlowieka.pdf (data dostępu: luty 2018) 


\section{Damian Wątrobiński: Dylemat audiodeskryptora $w$ procesie przekładu audiowizualnego}

dochodzi do konwersji medium wizualnego w medium audialne, następuje zatem zmiana systemu znaków. ${ }^{2}$ Ponadto audiodeskrypcja, obok $\mathrm{m}$. in. napisów, dubbingu i lektora, wpisuje się w tzw. tłumaczenie audiowizualne, które to, jak sama nazwa mówi, dotyczy tłumaczenia dzieł składających się z warstw dźwiękowej i (lub) wizualnej. Takie podejście do tematu deskrypcji pozwala również określić osoby tworzące opisy do produkcji (audio)wizualnych, audiodeskryptorów, jako tłumaczy, którzy muszą się zmagać $\mathrm{z}$ wieloma trudnościami translatorskimi $\mathrm{w}$ procesie przekładu. Mogą nimi być $\mathrm{m}$. in. sprostanie oczekiwaniom heterogennej grupy odbiorców (osoby niewidome od urodzenia versus osoby, które utraciły wzrok w późniejszym etapie życia), umiejętność technicznego i czasowego dopasowania tekstu audiodeskrypcji w filmie (tak, by nie zakłócać dialogu bohaterów), selekcja najważniejszych informacji, ich kolejność podawania (w przypadku obrazów nie możemy mówić o linearności przekazywanych treści), jak również trudność polegająca na tym, czy i jak nazywać emocjonalne stany bohaterów - jest to o tyle skomplikowane, że przekazywanie określonych emocji w audiodeskrypcji może zostać uznane za interpretację lub próbę manipulacji uczuciami osoby niewidomej, o czym będzie mowa w dalszej części artykułu.

Niniejszy artykuł poświęcony jest wyżej wspomnianej kwestii, tzn. jego celem jest ukazanie problemu przekazu emocji w thumaczeniu i samej audiodeskrypcji oraz $\mathrm{w}$ związku z tym wskazanie na dylemat towarzyszący tłumaczowi tworzącemu audiodeskrypcję do reprodukcji malarskich. Kwestia emocjonalności przekazu audiodeskrypcji zostanie przedstawiona nie tylko na płaszczyźnie teoretycznej, ale i również za pomocą analizy dwóch audiodeskrypcji, w trakcie tworzenia których audiodeskryptor musiał podjąć decyzję o zastosowaniu w tekście licznych środków językowych i pozajęzykowych implikujących emocje. Badania dokonane w ramach części praktycznej mają umożliwić nazwanie i wyjaśnienie funkcji emocjonalnie zabarwionych audiodeskrypcji. Jednakże wniosków przedstawionych w końcowej części artykułu nie należy rozumieć jako jednoznacznej odpowiedzi na pytanie, czy w trakcie tworzenia opisu do produkcji wizualnej audiodeskryptor powinien przede wszystkim zwracać uwagę na przekaz emocji, lecz jako teoretyczno-praktyczne ujęcie pełnej emocji audiodeskrypcji do reprodukcji malarskich powstałej z myślą o dzieciach i młodzieży. Praca ta ma również skłonić do dalszych dyskusji i refleksji nad prawdziwym znaczeniem i przesłaniem audiodeskrypcji, tworzonej przez tłumaczy, którzy muszą zmagać się z określonymi problemami.

\section{Tłumacz i jego przekład versus emocje}

Jednym z dylematów, którym tłumacz musi stawić czoła, jest kwestia dotycząca tego, w jaki sposób oddać emocje zawarte w oryginale. Dlatego też

2 O audiodeskrypcji jako intersemiotycznej formie przekładu audiowizualnego pisałem w: Wątrobiński (2017: 241-253). 
warto przyjrzeć się statusowi tłumacza oraz jego stosunkowi do emocji wyrażonych w oryginale.

Wyżej wspomniane zależności między tłumaczem a dziełem, które ma zostać poddane przekładowi, mogą się odnosić również do samego autora, którego utwór będzie tłumaczony. W literaturze wskazuje się bowiem na dwie osobowości, które spotykają się w procesie tłumaczenia - na tłumacza i autora (Tokarz 2015: 381), a co za tym idzie podczas przekładu dochodzi do spotkania dwóch (często różnych) kultur i dwóch światów. Spotkanie to jest sytuacją złożoną i stanowi pierwsze źródło emocji, które na samym początku towarzyszą tłumaczowi, pierwszemu odbiorcy danego dzieła. Idąc za ujęciem procesu tłumaczeniowego przez Tokarz, należy przywołać dwa zaproponowane przez nią rodzaje sytuacji, które wywierają wpływ na przekaz i docelowo na jego zabarwienie emocjonalne. Mowa jest o sytuacjach wewnątrztekstowych, czyli próbie „naśladowania przeżycia i ekspresji emocjonalno-intelektualnej” (Tokarz 2015: 381) podejmowanej przez tłumacza, oraz sytuacjach zewnątrztekstowych, czyli „stosunku emocjonalnym, artystycznym i intelektualnym tłumacza do poetyki oryginału i emocji w nich wyrażonych" (Tokarz 2015: 381). Warto więc w tym kontekście zwrócić uwagę na fakt, że emocje oddane w translacie nie muszą mieć wyłącznie swego podłoża w oryginale, ale mogą pochodzić od samego tłumacza, który jest osobą z określoną wrażliwością. Tłumacz to medium komunikacyjne, to on musi przeprowadzić procesy myślowe, by oddać charakter oryginału - jak pisze Tokarz, tłumacz „aktywizuje swój rozum, wiedzę, zmysły i emocje" (2015: 382). Z tego też powodu można mówić o względnej odpowiedzialności tłumacza wobec osoby autora (Tokarz 2015: 382), ponieważ tłumacz z jednej strony zobowiązany jest do wiernego oddania oryginału, a $\mathrm{z}$ drugiej zaś jego odpowiedzialność nazywana jest względną, ponieważ próba odcięcia własnych emocji w procesie przekładu jest trudnym wyzwaniem. Wyzwanie stanowi również sam język, za pomocą którego tłumacz oddaje tekst oryginału - język jest bowiem podstawowym narzędziem aktu komunikacji, acz również niedoskonałym, bo to $\mathrm{w}$ nim swoje odzwierciedlenie znajdują skrajne zdolności, czyli rozum, wyobraźnia i uczucie (Tokarz 2015: 383).

Powyżej zarysowane relacje pomiędzy tłumaczem, oryginałem a emocjami można również przenieść na grunt tłumaczenia audiowizualnego, a docelowo audiodeskrypcji.3 Bowiem to w ramach tworzenia deskrypcji dla reprodukcji malarskich (lub filmowych) dochodzi do spotkania dwóch światów - świata osób widzących oraz osób niewidomych i niedowidzących. Jeśli chodzi o podłoże emocji w audiodeskrypcji, trzeba zwrócić uwagę na audiodeskryptora jako pierwszego odbiorce obrazu malarskiego. To on dokonuje procesu myślowego oraz jako pierwszy dostrzega emocje zawarte w danym dziele wizualnym. Ponadto audiodeskrybent może mieć konkretne stanowisko względem oryginału i darzyć jego estetykę i styl świadomie, bądź nieświadomie określonymi emocjami. Na poparcie tych słów warto przytoczyć stwierdzenie, które pojawia się w literaturze dotyczącej

\footnotetext{
${ }^{3}$ Tematykę przekazu emocji w ramach audiodeskrypcji podjąłem w: Wątrobiński (2017: 241-253).
} 


\section{Damian Watrobiński: Dylemat audiodeskryptora $w$ procesie przekładu audiowizualnego}

audiodeskrypcji malarstwa: tłumacz, będący medium czyli pośrednikiem komunikacji, o czym była mowa powyżej, daje się również określić jako tzw. „pośrednik przeżycia” (Kęsicka 2014: 50). W kontekście audiodeskrypcji do reprodukcji malarskich wskazuje się również dwa inne aspekty, determinujace przekaz emocji w opisie audiowizualnym. Chodzi o brak określonej kolejności informacji podczas kontemplacji obrazu (Kęsicka 2014: 53), a co za tym idzie, brak linearności opisu audiowizualnego - to thumacz dokonuje subiektywnej selekcji informacji i decyduje o tym, w jakiej kolejności podawane są określone detale produkcji malarskiej. Emocje oddane $\mathrm{w}$ audiodeskrypcji zależą zatem $\mathrm{w}$ dużej mierze od samego dzieła jakim jest obraz oraz od tłumacza, który swoją autonomią w konstruowaniu zależności między obrazem a tekstem produkuje emocje (Kęsicka 2014: 55), znajdujące swój wyraz w środkach językowych.

\section{Przekaz emocji w audiodeskrypcji}

Pierwsze polskie standardy sformułowane przez B. Szymańską i T. Strzymińskiego (2010) zawierają szereg zalecanych praktyk dotyczących sporządzania deskrypcji. Warto zwrócić uwagę na trzy główne zasady, które powinny przyświecać audiodeskryptorom podczas tworzenia opisu do produkcji audiowizualnej:

„1. Opisz to, co widać na obrazie, co możesz na nim zaobserwować.

2. Nie interpretuj, nie przedstawiaj swoich wniosków, opinii ani motywów opisywanych postaci.

3. Nie mów w czasie dialogów. Wyjątek stanowią jedynie bardzo istotne akcje rozgrywające się na ich tle" (Szymańska, Strzymiński 2010: 19).

Polscy audiodeskryptorzy wskazują więc na ważność dokładnego i wiernego oryginałowi opisu. Co szczególnie istotne dla niniejszego artykułu, zgodnie $\mathrm{z}$ powyżej wspomnianymi standardami $\mathrm{w}$ audiodeskrypcji nie można przemycać żadnych interpretacji, które często idą w parze z próbą oddania emocji oryginału. W standardach jest kilka wzmianek dotyczących zaniechania oddawania jakichkolwiek odcieni emocji.

Podobne założenia, choć nieco bardziej techniczne i zadaniowe, reprezentują niemieccy audiodeskryptorzy z instytucji Deutsche Hörfilm $\mathrm{gGmbH}$, których standardy poruszają takie kwestie, jak unikanie fachowych sformułowań i odczytywania emocji z twarzy postaci. Warto w tym miejscu zacytować krótki fragment niemieckich standardów, które w zwięzły sposób oddają cel strategii stosowanych przez niemieckich tłumaczy audiowizualnych:

„Opis składający się na audiodeskrypcję powinien odpowiadać na cztery glówne pytania: kto?, gdzie?, kiedy?, jak?" (Benecke i in. 2015: 2)

Według powyższego audiodeskrypcja ma zatem podawać opis tego, co jest widoczne dla widzów - stawia się więc na jej techniczno-zadaniowy i informacyjny charakter. Odchodzi się od nazywania emocji, bowiem te są uznawane za próbę manipulacji i sugerowania konkretnej interpretacji osobom niewidomym. 
Powyższym założeniom przeciwstawia się Izabela Künstler, pionierka audiodeskrypcji w Polsce, prowadząca firmę Napisy-Audiodeskrypcja, która jest zdania, że audiodeskrypcja ma stanowić przeżycie dla niewidomego odbiorcy i dać jemu satysfakcję estetyczną (Künstler 2014: 142). Tłumaczka wskazuje na istotę emocji, które są „przetłumaczonymi znakami języka filmowego", co można osiągnąć dzięki zastosowaniu środków literackich (Künstler 2014: 143). AD ma zatem wywołać u niewidomych odbiorców te same lub podobne emocje, które towarzyszą widzącym odbiorcom. Wszystko powinno więc, zdaniem audiodeskryptorki, przebiegać w myśl katharsis - oczyszczenia, wtedy osiągniemy najważniejszy cel opisu audiowizualnego, a mianowicie poruszymy i wzruszymy niewidomego odbiorcę audiodeskrypcji.

Dylemat dotyczący przekazu emocji w ramach audiodeskrypcji towarzyszył innej audiodeskryptorce - Beacie Jerzakowskiej, która wydała publikację „Posłuchać obrazów”, a dokładniej rzecz ujmując, podręcznik z audiodeskrypcjami do 70 obrazów z myślą o uczniach - dzieciach i młodzieży. Tłumaczka musiała zdecydować się na określony, odważny sposób podejścia do kwestii emocji - tym samym zadała sobie pytanie, $\mathrm{w}$ jaki sposób dotrzeć do tak wymagających odbiorców jakim są dzieci i młodzież.

\section{5. (Poza)językowe przejawy emocji w audiodeskrypcji}

Pierwszą $\mathrm{AD} 4$, która zostanie poddana analizie na płaszczyźnie językowej $\mathrm{z}$ uwzględnieniem przekazu emocji, jest deskrypcja do tajemniczego i utrzymanego w mrocznym klimacie obrazu Samuela Hirszenberga pt. „Czarny sztandar”.

$\mathrm{Na}$ płótnie przeważają czarne i ciemne kolory, a większość emocji widocznych na obrazie można odczytać z twarzy przedstawionych postaci, ich gestów oraz wbudowanych w obraz symboli. Audiodeskryptorka rozpoznała elementy ukazujące tragizm i emocjonalizm sceny i oddała emocje w postaci słów, posługując się metaforami, a dokładniej rzecz ujmując, synestezjami, czyli opisami, które angażują kilka zmysłów jednocześnie. Zabieg ten uwidacznia się w następujących fragmentach AD: „Realistyczny obraz przedstawia morze ludzi. Suną z głębi, od prawej strony obrazu do lewej” oraz „Nawet niebo zdaje się ponure i ciemnoszare, przykryte ciężkimi chmurami”. Zastosowanie synestezji wzmacnia odbiór obrazu i stanowi dla niewidomego ucznia dodatkowy bodziec percepcji i odniesienia. Warto w tym kontekście przywołać badania, które prowadził amerykański neurolog, Vilayanur Subramanian Ramachandran. Badacz ten koncentruje się w swojej pracy naukowej na percepcji wzrokowej, a najbardziej znany jest z podejmowania refleksji na temat roli synestezji. Według amerykańskiego naukowca zjawisko synestezji uaktywnia

4 Wszystkie cytaty audiodeskrypcji przytoczone w tym rozdziale pochodzą z książki „Posłuchać obrazów” Beaty Jerzakowskiej (2016). 


\section{Damian Wątrobiński: Dylemat audiodeskryptora $w$ procesie przektadu audiowizualnego}

w naszym mózgu określone połączenia, które pozwalają na kombinację doznań wynikających z różnych zmysłów (Ramachandran 2005: 509-520).

Trafny dobór czasowników zastosowanych w wyżej cytowanym fragmencie $\mathrm{AD}$ oddaje technikę malarską, za pomocą której został przedstawiony pochód postaci. Poza tym takie metafory, jak np. „morze ludzi”, wymagają od niewidomego ucznia pewnej wiedzy językowej lub zachęcają do zadania pytania, jeśli zwrot ten nie jest przez niego znany.

$\mathrm{W}$ omawianej $\mathrm{AD}$ pojawia się $\mathrm{w}$ kilku miejscach jedna $\mathrm{z}$ najbardziej typowych strategii translatorskich $\mathrm{w}$ tworzeniu deskrypcji, a mianowicie opis od ogółu do szczegółu. W tym kontekście warto zacytować następujący fragment AD: „W tle, na linii horyzontu, którą tworzą kapelusze żałobników, na wysokości jednej trzeciej od góry obrazu, wyeksponowana i okryta czarnym sztandarem, widoczna jest trumna”. Na samym wstępie można stwierdzić, że zdanie to brzmi nieco nienaturalnie lub jest nawet niepoprawne, ponieważ jego składnia została w pewien sposób zaburzona. Ten zabieg stylistyczny ma jednak określony cel. Mianowicie główny nośnik emocji, jakim jest w tym zdaniu trumna, ma dotrzeć do niewidomego odbiorcy jak najpóźniej, na samym końcu. Najpierw dowiaduje się on, gdzie dana rzecz się znajduje i jakie ma atrybuty, a dopiero w ostatnim momencie skonfrontowany jest $\mathrm{z}$ główną informacją. Taka strategia opisu ma wprowadzić nastrój grozy, zbudować napięcie, nadać opisowi dynamizmu oraz wzbudzić nastrój niecierpliwości i oczekiwania u niewidomego odbiorcy. Ma też zachęcić do próby odgadnięcia, czym jest dany przedmiot.

Obraz Samuela Hirszenberga jest niezwykle mroczny, ponury, pełen niepokoju i niedopowiedzeń. Audiodeskryptorka chciała oddać klimat tego dzieła, dlatego posłużyła się w swoim opisie przysłówkiem „niewykluczone”, partykułami „może” i ,jakby” oraz wyrażeniem przymiotnikoworzeczownikowym „niezdefiniowany blask” - taki dobór leksyki nadał opisowi odcień przypuszczenia, wątpliwości i niedopowiedzenia, co z kolei zmusza niewidomego odbiorcę do zaangażowania się $\mathrm{w}$ percepcję emocjonalną reprodukcji i jej interpretację. Nie można zatem stwierdzić, że $\mathrm{AD}$ ta jest pełna gotowych odpowiedzi i interpretacji, zawiera ona sugestie - to od niewidomego ucznia zależy, czy wybierze którąś z propozycji odczytania, czy zaproponuje swoje własne podejście do dzieła Hirszenberga.

Analizując AD do obrazu Hirszenberga, nie można zapomnieć o krótkich i precyzyjnych zdaniach, składających się na opis, co powoduje, że AD jest dynamiczna. AD do obrazu Czarny sztandar utkana jest z odważnej strategii stylistycznej mającej na celu przekaz emocji i skłonienie do głębszych rozmyślań. Mowa tutaj o pytaniach retorycznych, z którymi niewidomy odbiorca jest skonfrontowany, jak np.: „A może coś krzyczą z przerażeniem?". Audiodeskryptorka świadomie łamie podstawowe zasady tworzenia opisów do produkcji audiowizualnych, bowiem wprowadza do swoich $\mathrm{AD}$ elementy niepewności i praktycznie rzecz biorąc sama zastanawia się nad wydarzeniami przedstawionymi na płótnie. W ten sposób niewidomy uczeń zostaje niejako zaproszony do snucia domysłów i interpretowania obrazu. Ciekawym zabiegiem zastosowanym przez autorkę są też bezpośrednie zwroty do ucznia, co widać np. w zdaniu: 
„Spogląda w stronę widza”. Niewidomy odbiorca zostaje w ten sposób bezpośrednio zaangażowany w emocjonalną percepcję obrazu.

W przypadku AD do obrazu Samuela Hirszenberga można również mówić o szerokim spektrum czynników paratekstualnych, które wpływają na emocje odbiorcy. W tło $\mathrm{AD}$ do Czarnego sztandaru została wkomponowana cicha, delikatna i żałobna muzyka, która nasila się w połowie deskrypcji. Przy wypowiadaniu słów, które nazywają emocje zarysowujące się na twarzach postaci, zaczyna być słyszalny wysoki i przejmujący dźwięk gitary. Muzyka utrzymująca się przez całą AD jest przytłumiona, sprawia wrażenie, jakby dochodziła z daleka - zza tłumu ludzi przedstawionych na płótnie. Ton głosu lektora jest poważny, jednostajny i powolny - znakomicie odwzorowuje pochód pogrążonych w smutku postaci.

Druga audiodeskrypcja, która zostanie zbadana pod kątem językowym, została napisana do wstrząsającego obrazu Andrzeja Wróblewskiego Rozstrzelanie $V$. W tej deskrypcji można zauważyć trzy wiodące strategie translatorskie, które stanowią o emocjonalności opisu. Po pierwsze należy zwrócić uwagę na określony dobór przymiotników. Z jednej strony są one odpowiednio nacechowane, $\mathrm{z}$ drugiej zaś dostarczają informacji np. o rozmieszczeniu treści na obrazie - jako przykład można podać w tym kontekście określenie „ciasny kadr”. Po drugie w opisie tego obrazu audiodeskryptorka posłużyła się znów synestezjami, które uwidaczniają się w takich wyrażeniach, jak: „zimny kolor niebieski” oraz „z obrazu bije dramatyczna cisza”. Odwoływanie się do innych zmysłów jest znakomitym pomysłem, aby w ten sposób poruszyć emocje u niewidomego odbiorcy i zaangażować go jeszcze bardziej w odbiór obrazu. Po trzecie niezwykle istotnym elementem w przekazie emocji są w tej deskrypcji wyliczenia, które budują dynamizm opisu i niejako wciągają niewidomego odbiorcę $\mathrm{w}$ percepcję dzieła. Jako przykład należy tutaj podać następujący fragment AD: „Przed stojącymi bohaterami, przy ich nogach, na zielonym gruncie, leży rozczłonkowane, brutalnie zdeformowane, niemal dosłownie zdezintegrowane, ciało trzeciej postaci”. W przypadku tego zdania należy wyszczególnić jeszcze dwa inne aspekty. Główna informacja została przerzucona na koniec zdania, by zaskoczyć niewidomego odbiorcę, co było już wspomniane w niniejszym artykule. Jednak dokładniejszego komentarza wymaga nagromadzenie słów, które w swojej budowie zawierają twardą spółgłoskę $r$, należącą niewątpliwie do najbardziej ekspresywnych dźwięków w języku polskich (rozczłonkowane, brutalnie zdeformowane, zdezintegrowane). To właśnie spółgłoska $r$ stanowi element emocjonalności i ekspresji tej $\mathrm{AD}$, co więcej, kojarzy się nam złowrogo, bo występuje w dwóch polskich popularnych wulgaryzmach (Mackiewicz 2010). W przypadku wypowiadania słów zawierających spółgłoskę r, przenoszony jest na obszar języka swego rodzaju dynamizm i ruch. Jak pisze Łukasz Mackiewicz (2010), spółgłoskę [r] klasyfikujemy jako spółgłoskę drżącą, czyli taką, która niesie ze sobą określony ładunek emocjonalny. 


\section{Damian Wątrobiński: Dylemat audiodeskryptora $w$ procesie przekładu audiowizualnego}

Nagromadzenie spółgłoski $r$, o czym mowa powyżej, można odnieść do elementów pozajęzykowych zastosowanych $\mathrm{w}$ badanej $\mathrm{AD}$. Lektor wypowiada te słowa niezwykle dosadnie i kładzie akcent na każdą ze spółgłosek $r$, co powoduje, że słowa te jeszcze mocniej wybrzmiewają. W tle AD znów słychać przeszywający, stłumiony, bliżej nieokreślony dźwięk. Co ciekawe, głos lektora lekko załamuje się i ścisza w momencie wypowiadania słowa „cisza” oraz jest pełen współczucia podczas wypowiadania słów „chłopiec” i „spodenki”. To wszystko nadaje opisowi większej głębi oraz wzbudza podobne emocje u odbiorcy.

\section{Podsumowanie}

$\mathrm{Z}$ wyżej przeprowadzonej analizy jednoznacznie wynika, że zaproponowane przez tłumaczkę deskrypcje są pełne środków językowych, literackich, jak również elementów paratekstualnych, których głównym zadaniem jest jak najwierniejszy i najpełniejszy przekaz emocji.

Jeśli chodzi o funkcje takiego rodzaju audiodeskrypcji, pierwsza z nich to na pewno funkcja artystyczna. Dobrane przez audiodeskryptorkę słowa składają się na opis, który ma zastąpić warstwę wizualną wyjściowego dzieła - ma przekazać te same emocje i oddać możliwie jak najwięcej treści zakotwiczonych w obrazie. Jeśli jednak mówimy w dodatku o AD do reprodukcji malarskich, wchodzących w skład Podstawy programowej dla uczniów gimnazjum i liceum, możemy zaobserwować szereg kolejnych funkcji, którymi wyróżnia się opis dokonany przez autorkę książki Postuchać obrazów.

Niewątpliwie badane $\mathrm{AD}$ niosą ze sobą funkcję edukacyjną, ponieważ stanowią uzupełnienie kształcenia literackiego, językowego i emocjonalnego uczniów. Warto również zwrócić uwagę na funkcję pragmatyczną badanych $\mathrm{AD}$, na co wskazuje sama autorka publikacji (Jerzakowska 2016: 21). Audiodeskryptorka świadomie łamie określone standardy tworzenia audiodeskrypcji, dodając do opisów pytania retoryczne, metafory, synestezje i szereg innych środków stylistycznych. Ponadto dydaktyzm i próba przekazu emocji uwidaczniają się również w warstwie brzmieniowej tekstu oraz w muzyce wkomponowanej w każdą z AD. Deskrypcje są odczytywane przez lektora z odpowiednią intonacją, zaangażowaniem, tempem, a jego barwa głosu zmienia się w zależności od treści opisu i określonych słów. Można zatem stwierdzić, że wspomniane elementy paratekstualne niosą ze sobą silny aspekt dydaktyczny. Deskrypcje są bowiem przewidziane dla uczniów gimnazjum i liceum, czyli dzieci i młodzieży, a teksty tworzone z myślą o takiej grupie odbiorców powinny być interesujące, angażujące i dostosowane do ich potrzeb (Iser 1994).

Reasumując należy jednoznacznie stwierdzić, że AD zaproponowane przez Beatę Jerzakowską ukazują odważne i nietypowe podejście do tematu przekładu dla osób niewidomych. Odwaga ta była jednak uzasadniona i przyczyniła się do powstania cennej i wartościowej publikacji, która pozwala niewidomym uczniom pogłębić ich wiedzę, ale i również doświadczyć emocji 
związanych z percepcją sztuki - emocji tych samych, które towarzyszą osobom widzącym, choć wywołanych poprzez inne kanały zmysłowe.

Jeśli zaś chodzi o kwestię emocji i ich przekaz w tłumaczeniu audiowizualnym, warto zadać sobie pytanie, dla jakiej grupy odbiorców tworzony jest dany opis. W końcu to zdanie osób, do których kierowana jest audiodeskrypcja, powinno się liczyć dla tłumacza - chcąc zaangażować dzieci i młodzież w percepcję obrazów przekazywanych słowem, trzeba sięgnąć po wyjątkowe i odważne środki językowe. 


\section{Damian Wątrobiński: Dylemat audiodeskryptora \\ $w$ procesie przekładu audiowizualnego}

\section{Bibliografia}

Benecke, B., Horbach, D., Wiemers, M., Müller, L., Brons, K., Linder, P. i inni. (2015). Vorgaben für die Erstellung von Audiodeskriptionen. Berlin: Auftrag an den NDR/ARD.

Iser, W. (1994). Der Akt des Lesens: Theorie ästhetischer Wirkung. Stuttgart: UTB $\mathrm{GmbH}$.

Jakobson, R. (1971). Selected Writings Word and Language. Paryż: Walter de Gruyter.

Jerzakowska, B. (2016). Postuchać obrazów. Poznań: Wydawnictwo Rys.

Kęsicka, K. (2014) Bilder mit Worten gemalt - zur Problematik der Audiodeskription als einer Form der Übertragung von Kunst, w: Studia Germanica Posnaniensia XXXV. Poznań: Uniwersytet im. Adama Mickiewicza w Poznaniu, pp. 53-57.

Künstler, I. (2014). Cel uświęca środki audiodeskrypcji. w: Przekładaniec Audiodeskrypcja, pp. 140-153.

Mackiewicz, Ł. Brzemię brzmienia, czyli warstwa brzmieniowa tekstu: httpwww.ekorekta24.pl/brzemie-brzmienia-czyli-warstwa-brzmieniowatekstu-jak-i-po-co-ja-wykorzystywać (data dostępu: luty 2018).

ONZ. Powszechna Deklaracja Praw Człowieka: http://www.unesco.pl/fileadmin/ user_upload/pdf/Powszechna_Deklaracja_Praw_Czlowieka.pdf (data dostępu: luty 2018).

Ramachandran, V. S. (2005, Listopad 3). Neurocognitive Mechanisms of Synesthesia, w: Neuron, pp. 509-520.

Szymańska, B. i Strzymiński, T. (2010). Standardy tworzenia audiodeskrypcji do produkcji audiowizualnych. Białystok: Audiodeskrypcja.

Tokarz, B. (2015) Tłumacz, emocje i przekład, w: Poznańskie Studia Slawistyczne 9. Poznań: Publishing House of the Poznan Society for the Advancement of the Arts and Sciences. pp. 381-385.

Walczak, A. (2012) Deskryber? Audiodeskryber? A może audiodeskryptor? O nowym zawodzie - twórcy audiodeskrypcji. Warszawa: Uniwersytet Warszawski.

Wątrobiński, D. (2017) Komunikacja emocji w tłumaczeniu audiowizualnym. Audiodeskrypcja do filmu W ciemności Agnieszki Holland, w: Przekład i emocje (Studia o przektadzie, nr 45). Katowice: Wydawnictwo Naukowe „Śląsk”, Stowarzyszenie Inicjatyw Wydawniczych, pp. 241-253. 